\title{
Embryo Disposition and the New Death Scene
}

\author{
DAVID ELLISON AND ISABEL KARPIN \\ GRIFFITH UNIVERSITY AND UNIVERSITY OF \\ TECHNOLOGY, SYDNEY
}

A perplexing and sometimes distressing indeterminacy shadows the scene of death in the early twenty-first century-a scene that had once been characterised by a reasonably firm sense of finality. Take, for example, the concept of 'brain death' that has enabled the extension of life through organ donation. Consider also the extraction of 'live' sperm from the recently deceased in order to create posthumous embryos. These are both constructed biotechnological effects that give rise to new inconclusive death scenes that in turn provoke novel legal and cultural responses.

Another such death scene, and the one with which we are principally concerned in this essay occurs in the IVF clinic.

In the IVF clinic, a place designed principally for the production of life, clinicians and IVF recipients are faced with a dilemma-how should they dispose of those embryos that, for a variety of reasons, are deemed surplus? As we write there are thousands of cryopreserved embryos awaiting such disposition decisions. ${ }^{1}$ The options for disposition are many. Embryos may be thawed for transfer, they may be donated for research or for use by other infertile people, they may remain frozen, or 
they may variously be allowed to-and here the choice of words is telling'succumb', 2 be disposed of, ${ }^{3}$ or allowed to die. ${ }^{4}$

Here, we consider those disposition methods that involve some form of ethical management and memorialisation. We argue that what is being managed and memorialised constitutes a death scene of sorts-one where death itself is curiously absent. It is a death scene where the potentiality of that which has not lived is acknowledged yet purposely denied the luxury of a fully realised narrative. Ontic recognition is tied to a ceremonial foreshortening. We offer an account of the medical, cultural and legal management of this 'death scene' and ask how 'deaths' are produced through interaction with surplus embryos: not as a life lost, but as something else.

\section{-EMBRYO DISPOSITION}

Methods of embryo disposition vary according to the legal and clinical regimes in place. In Australia, for example, the National Health and Medical Research Council's Ethical Guidelines on the Use of Assisted Reproductive Technology in Clinical Practice and Research (NHMRC ART Guidelines) and various pieces of state legislation place a time limit on the storage of cryopreserved embryos. ${ }^{5}$ While in other jurisdictions, such as some states in the United States, it may be possible to continue cryopreservation indefinitely (assuming the costs can be met), in Australia it seems clear that all patients with cryopreserved embryos must make a disposition decision at some point. In the absence of a directive, clinics are required to dispose of cryopreserved embryos after the requisite time period has expired. As noted at the outset, disposition options include donation of the embryo for research and donation to another person or couple for their reproductive use. Where a person decides instead to dispose of their embryos permanently through discard there are a number of different methods that are available. We are most interested in a method of disposition that relies on the female body to provide an end point for the embryo. In such cases the clinic transfers the surplus embryo either into the woman's vagina where it cannot develop further, or into her uterus at a time when implantation is unlikely and without the benefit of fertility-enhancing hormones. Alternatively, in jurisdictions where the law permits, some women might elect to extend 
cryopreservation until the onset of menopause-at which point the embryo is transferred on the understanding that implantation will not occur. ${ }^{6}$

These methods of disposal are sometimes referred to as 'compassionate transfer'. The term 'compassionate transfer' has appeared in the literature concerning IVF practices in the United States fairly recently and seems to have become the accepted description there. Anne Drapkin Lyerly et al. refer to it in their 2008 article detailing a 2007 study on patients' views of embryo disposition.7 The term was made popular by Resolve: The National Infertility Association in the United States, who list 'compassionate transfer' on their website among the available options for IVF patients with frozen embryos awaiting disposition decisions. ${ }^{8}$ It is also likely that the practice (if not the term) actually arose earlier, in Europe, where clinics operating in countries like Switzerland were seeking to manage restrictive legal regimes and maximise embryo transfer and implantation success rates.

The Swiss Reproductive Medicine Act, which came into force in 2001, prohibits cryopreservation of embryos in most circumstances. ${ }^{9}$ This prohibition, together with the requirement set out in Article 119(2)c of the Swiss Constitution that 'no more human egg cells may be developed into embryos outside the woman's body than are capable of being immediately implanted into her', means that Swiss clinics are required to transfer all embryos into the woman's body at the time they are created, if possible. ${ }^{10}$ When the legislation came into effect most IVF clinics were cultivating at least three fertilised eggs into embryos to ensure that at least one was suitable for transfer. As the technology was not sufficiently advanced to determine with accuracy which fertilised eggs would successfully develop into cleaved embryos (embryos whose cells had begun to divide), three were developed with the intention of selecting the best two for transfer. In order to abide by the letter of the law and avert the risk of triplets, the third and remaining embryo was 'implanted into' (in compliance with the wording of Article 119(2)c of the Swiss Constitution) the woman's vagina where it could not develop further. ${ }^{11}$ This is how the practise was described by 'H.', one of a number of women interviewed in a study conducted by Scully et al.: 'The rest of the embryos, they said they would simply put them back in the vagina, so they come to an ethical end, somewhere.'12 Note that not only does 'H.' draw on a discourse of 'ethical ends' but she also refers to the embryo as 
returning-it is 'put back'-even though the embryo (in that form) has never actually been inside her body in the first place. In somewhat more clinical terms the practice has been described by the director of the Division of Reproductive Endocrinology and the Department of Obstetrics and Gynaecology at the University Hospital Zurich, Professor Bruno Imthurn, as follows:

From the legal and biological point of view it is the same to discard embryos or to replace them into the vagina. In both situations they are destroyed. However, for many patients (and also for me) it is a difference from their (and my) ethical point of view, whether to put the embryos in a garbage bin or returning them to the body of the corresponding patient. ${ }^{13}$ While 'H.' clearly draws on the vocabulary of the clinic as modelled by Imthurn, her account differs to the degree that it is marked by uncertainty. Her version appears more tentative, conjuring an ethical end, 'somewhere'. Arguably, 'H."s tentative response suggests that the ethics produced out of this bodily procedure are far from self-evident. Studies by Lyerly, de Lacey, Haimes and Scully, among others, have shown that the value accorded to embryos by the clinicians and gamete providers who jointly create them is replete with uncertainty and indeed ambivalence. ${ }^{14}$ The transformation then, of this essentially strategic, if not evasive, clinical practice into an 'ethical' and 'compassionate' one raises complex questions that require further interrogation.

\section{-'COMPASSIONATE TRANSFER' AS ETHICAL PRACTICE}

We consider two quite different responses to the practice of compassionate transfer that we outline below. First, the idea of the ex utero in vitro cryopreserved embryo's 'return' to the female body reminds us that its disconnection from that body is a technological artefact. As Karpin notes elsewhere:

The embryo is only connected with its potential for personhood by female embodiment. Those who wish to make the argument that all embryos have equivalent value do so only by rendering the female body irrelevant. ${ }^{15}$

In this way, the return of surplus embryos to the female body for their disposal ironically 'acknowledges' the pivotal role of female embodiment as the precondition of their potentiality. It is both a starting and a stopping point. The potential life status of the embryo is contingent at best on female decision making and the 
embodied progress of pregnancy. The clinic orchestrates a ritual that aligns their disposal objective with the waste and renewal cycles of the female body. Something between menstruation and miscarriage is gestured towards in this procedure known as 'compassionate transfer'. But it is not just the clinic that sees these alignments. Some women who have spoken about their decision to dispose of surplus embryos, rather than donate them, have likened the disposition decision to their experience of the ordinary cycles of loss in pregnancy. In Sheryl De Lacey's study, for example, she quotes first 'Sue' and then 'Louise' who discuss their decision to discard:

Sue: There's an aspect of uncertainty anyway. Would they have taken [had we put them back]? There's still a chance factor in there because not all transfers take.

Louise: they certainly don't always take anyway. They, you know, just die when you thaw them out quite often. ${ }^{16}$

De Lacey then notes that[rather than being concerned about waste, 'the "Discard" group perceived waste in reproduction (especially IVF) to be normal'.17 In this instance the embodied nature of loss is transposed across the clinical practice of disposition. We can see, therefore, how the step of placing or, notionally at least, 'returning' the embryo to the woman's body might be construed as 'compassionate'. It is a means of recasting as 'natural', and so to some extent beyond control, an artificially created and regulated cycle of production and loss. What is not clear in the practice of compassionate transfer is who in this arrangement extends compassion to whom? We will return to this below.

A second possible reading of this practice of compassionate transfer is to view the 'return' of surplus embryos to the female body as treating the receptive body as crypt. Given the understanding that this procedure cannot produce a child, placing the thawed embryo in the female body effectively re-sets the clock to a moment prior to the clinic's technological intervention, where failed reproduction and loss were the likely or inevitable outcome of attempted pregnancy. However, in this instance what was a pathologised inability to create and sustain life is redeemed as the mechanism and means of an ethical terminus. 
In order to pin down which of these two possible responses (while acknowledging the possibility of others) we find more compelling, we need to turn to the participants and how they view this practice.

While the various participants required for compassionate transfer to occur appear clear enough - the woman, joined perhaps by her partner or family member, and a clinical staff member-it is harder to identify the addressee of the ritual. Is it for the patients who are faced with these disposition decisions? Is it for the clinician, who may or may not have issues of conscience regarding the routine disposal of embryos as medical waste? Or is it on the behalf of the embryo itself?

We think that compassionate transfer might offer a way of valuing the loss of an embryo-paradoxically through the disposition decision itself-because it solemnises loss in the context of a purposeful giving up. There is value found or at least considered in these embryos-but not, we argue, as life lost, but as something different. That value is quite distinct from that used to sustain a right to life argument where one mourns the disposed embryo as an extinguished life. In contrast, the starting premise of 'ethical' disposal countenances the capacity to value embryos without according them life. Insofar as anti-abortion activists have weighed into the question of surplus embryos, they have characterised them as imperilled and in need of rescue or adoption. The failure to do so is described as equivalent to the avoidable death of a person. ${ }^{18}$ In this 'right-to-life' frame there can be no ethical end, as Imthurn describes it. Rather, all such ends are tragic and produce a measure of culpability. Within the clinic, in the context of 'compassionate transfer', this is not the case. Instead those ends are a deliberate technological and discursive moment created to mark the loss of something that there is no need (or desire) to keep or rather continue to store. What is mourned, celebrated, ceremonialised, ethicised is the loss (to the mother/father/clinic) of something that has been voluntarily forfeited.

Neither fully living nor dead, subject nor object, the surplus embryo destined for disposal occupies a peculiar position in terms of the affect its clinical ceremonies conspire to elicit. In this light, compassionate transfer bestows and erases animacy at the same moment. It gives the subjective impression of life and life's ending where there is neither. 
—OTHER DISPOSITION PRACTICES

'Compassionate transfer' is but one of a number of ways of structuring disposition events that seek to acknowledge embryo loss and create a ritual or meaningful practise.

Fenella Souter, writing in June 2009 in the Sydney Morning Herald, described how a particular family elected to dispose of their surplus cyropreserved embryos:

One by one that day, the family viewed the embryos through the microscope ... After the viewing, the Archibalds poured the contents of the Petri Dishes into a potted Azalea that they'd brought with them. They took the bush home, waited for spring, and planted it in the backyard. ${ }^{19}$

Note here how the attempt to create a mourning object shares a common grammar of display with the implantation procedure-much as funerals and weddings borrow from each other's grammar of spectacle. The viewing of the embryo through the microscope, followed by the empty Petri dish, resemble the clinical practice followed during an embryo transfer performed in the expectation of implantation and pregnancy. There the woman, separated from the sterile room where the embryo is thawed in preparation, is typically given the option to view the embryo prior to transfer. Generally this involves viewing a screen displaying the thawed embryo in a Petri dish, then, post-transfer, a confirmatory close up of the now empty dish. ${ }^{20}$

There is much more to say about this but here we are most interested in the composition of the ethical act. Notably, in the Archibald's case, unlike those where so-called compassionate transfer occurs, there is no intermediating act of female embodiment. That this could be a death scene at all is complicated by the fact it seems to borrow from few if any of our accepted conventions governing the end of life. These come readily to mind, either in their ideal form-we might think here of palliative care-or in the dreaded and frantic melee of the ICU: of intubation, or other invasive resuscitation efforts in the absence of a meaningful prospect of recovery. To this, one might add other representations of death that are, of necessity, missing from the disposition ceremony: the closing of eyes, the cessation of breath, the coming of pallor, the dwindling of heat. All of these signs play an important role in our understanding of death and yet none of them governs the 
scene we've chosen that ends not with a corpse, but with a pipette, Petri dish or vial. This is a 'death' without a body or, rather, it is a stage, almost more temporal than physical en route to embodiment; it is invisible yet visualisable, it can be made to pass from a state of apparent life to a state of apparent death by exposing it to nothing more taxing than room temperature. It is an imperfect state between liquid and solid. Paradoxically, the end of the embryo is composed out of the same elements and employing the same materials that signal the inaugural potential for life as it is framed in the IVF clinic.

-THE SCIENCE Of EMBRYo LAW

In order to understand how this end scene emerged as a necessity it is worth considering the pressure produced by the highly regulated and burgeoning number of cryopreserved embryos.

Currently in Australia (as in the US and the UK) there are many thousands of embryos in cold storage. ${ }^{21}$ These are the product of IVF programs where multiple embryos are created to give the woman the greatest chance of achieving a live birth. In 2007 for example, there were 56,817 ART treatment cycles reported in Australia and New Zealand and of these treatment cycles, 22.6 per cent $(12,815)$ led to a 'clinical pregnancy' and 17.4 per cent resulted in a live delivery. ${ }^{22}$ Typically, during IVF the woman is given hormone therapy to increase the number of eggs produced in a single cycle. These eggs are harvested and fertilised to create embryos. Some embryos, assessed as non-viable, will not make it past this stage in the process.

Although beyond the scope of this essay, it is worth noting that embryo disposition decisions proliferate throughout the IVF process. Consider, for example, what is at stake when an embryologist makes a visual assessment of an embryo to determine its quality for transfer or cryopreservation and decides against both. ${ }^{23}$ Such a routine disposition decision is typically characterised as uncontroversial and does not necessitate respectful framing of these actions in terms of loss. This process of so called 'embryo grading' is a developing technology with limited evidence of its efficacy. ${ }^{24}$ A similar outcome occurs for those embryos that undergo single cell biopsy—otherwise known as preimplantation genetic diagnosis (PGD)that are found to contain a defect. ${ }^{25}$ They too are disposed of without ceremony. These embryos might be construed by those attuned to disability rights as subject to 
radically normativising discourses that favour the consignment of the nonnormative to oblivion. ${ }^{26}$ Importantly, however, and contrary to anti-abortion rhetoric, it is not the value inherent in embryonic life that the disability theorist might mourn but the value of the possibility of non-normative life itself.

In the literature we have examined so far there is no ceremony that has been developed to attend to the disposition of these non-normative 'embryos'. For instance, Robert Shabanowitz, an embryologist from Geisinger Medical Centre in Pennsylvania, describes his 'angst' in response to discarding cyropreserved embryos while merely noting in passing the inevitable disposal of those that are, in his view, nonviable:

Disposing of human embryos is one of the more difficult responsibilities assigned to an embryologist in a fertility clinic. Disposal is not performed without a certain amount of angst; embryologists, after all, are primarily charged with the culture and transfer of embryos, not their destruction. Although we routinely discard embryos that are considered nonviable or fail to develop in culture, disposing of cryopreserved embryos represents those embryos that are considered to have the greatest potential for implantation...27 [emphasis added]

Thus, those embryos that receive a low grade or are found to carry a genetic flaw are routinely and unceremoniously discarded. In other words, they are pre-emptively dead in the way that viable embryos are accorded a presumptive claim to life that is confirmed or ratified in their cryopreservation. ${ }^{28}$ In this economy of embryonic value clinics and patients are given room to attend to the loss of those embryos that were rated highly enough to warrant cryopreservation, but are assumed to have no investment in the fate of imperfect embryos. Indeed this is simply seen as a clinical determination.

Setting aside those instances where PGD is involved, typically, after the rating process is complete and one or possibly two embryos are chosen for transfer, the patient might, as noted above, be given the option of cryopreserving the remaining embryos for later use, which may or may not eventuate. ${ }^{29}$ It is not until the patient's clinical engagement with IVF is at an end or when a legally determined storage time limit has expired that gamete providers are prompted to make a disposition decision in relation to any remaining cryopreserved embryos. At this 
point, the language shifts from the scientific and instrumental language of the clinic to a strangely imprecise language of affect. Disposition decisions, including compassionate transfer, describe allowing the embryos to 'thaw', 'succumb', and finally 'die'. But what does it mean here to speak of embryo death? This is a moment not so much where death is brought to life but rather where life is undone.

\section{-DEFINING EMBRYO DEATH}

How, if at all, can an embryo be said to die? Defining an embryo depends very much on where you stand in relation to it. Scientists who view the embryo as a source of cells for research will have one view, the embryologist working with embryos in the IVF clinic another, people variously called parents, gamete providers, couples, and donors who are directly related to the embryo will have yet more, and so on through to interest groups, lobbyists and the community at large. ${ }^{30}$

For the gamete providers perspective consider Jan Archibald, the woman who potted her embryos with an azalea and who, even as an observant Baptist, was clearly struck by the non-corporeality of her potential progeny and its incapacity to participate in the meaningful metaphors of life that attach to organic structure. In her view, the absence of a heart forecloses any metaphysical speculation about the status of the embryo: 'For us, there wasn't an issue with destroying embryos because there wasn't a heart ... They were only four cells. A heart, I think, is your soul; that's how we viewed it.'31

While the lines between life and death appear reasonably clear here, they are less so from a clinical perspective. There, a 'dead' embryo might be described as one in which development is 'arrested'. In other words, cell division has ceased. But it may be that an embryo with 'arrested development' is still metabolically 'active' even though it is no longer dividing. Stephen Minger, a stem cell researcher at Kings College, London, writing in the context of the ethical use of embryos for stem cell research, described them as follows: 'They are arrested, but still metabolically active ... So technically they are still alive, and to spin it bio-politically as an ethical source of hESC's [human embryonic stem cells] is completely misleading.'32 The embryo, then, whatever it is, occupies a hinterland between activity and inactivity rather than the clearer boundaries of life and death. Even in circumstances where it appears to have arrested it may be returned to viability through some further 
technological intervention. In this way, it continues to be technologically (re)created. David Wasserman describes the process by which they may be reactivated as akin to defibrillation:

In the case of 'dead' embryos, there may be ways to jump-start embryos that have arrested cell division, much like a defibrillator can be used to jump start an individual with cardiac arrest. If so, an arrest in cell division does not necessarily mean the embryo is dead. ${ }^{33}$

The artificiality of embryo death is as important as its artefactual life. In this way, we argue, it is the moment of dispositional decision making that actually enacts and constitutes the death scene rather than a biological or a physiological event.

We would like now to turn to the end scene itself and those who create it: the dispositional decision makers.

\section{-DISPOSITIONAL DECISION MAKERS}

Dispositional decision makers are those people who at some point will be required to make a decision about what is to done with their unused cryopreserved embryos. Patients may not contemplate this question until contacted by the clinic to pay a storage bill or because a legally mandated storage time limit has past and the clinic requires a disposition decision. Sheryl De Lacey's studies have shown that more often than not patients avoid disposition decisions for as long as they can. She describes how in the United States regulatory bodies have 'taken the step of defining an abandoned embryo and allowing such embryos to be legally discarded, provided that diligent attempts have been made to contact their owners and there are no advance directives'. ${ }^{34}$ In Australia, there are legal limits placed on embryo storage that determine the time frame in which a dispositional decision will have to be made about cryopreserved embryos. ${ }^{35}$ Although the law in Australia differs from state to state, it is generally silent about the act of embryo disposition itself. Victoria is one of the few exceptions. Section 34(2) of the Assisted Reproductive Treatment Act 2008 states:

A person who removes from storage an embryo that is not to be used for a treatment procedure must ensure that-

(a) it is not removed from its container, other than for the sole purpose of observing the embryo; and 
(b) it is disposed of in accordance with the regulations. ${ }^{36}$

The penalty for non-compliance is severe with a maximum of two years imprisonment. The regulations further require that 'an embryo must be disposed of by allowing the embryo to stand in its container, at room temperature, in a secure area for a period of not less than 24 hours' ${ }^{37}$

The only other state that explicitly referred to disposition decisions was South Australia which had required that 'persons on whose behalf a human embryo is stored outside the human body must have the right to decide how the embryo is to be dealt with or disposed of...'38 Amendments to the Act that came into effect in September 2010 have deleted these provisions. The new provisions are silent on methods of disposition. ${ }^{39}$ This is also the case in Western Australia and New South Wales where there is nothing explicit in the legislation to indicate how embryos will be disposed of. The Western Australia Reproductive Technology Council website does offer the following advice in response to a sample question:

Q: When I have finished my treatment and have embryos left over that I no longer need what are my options?

A: You may give consent to have the embryos removed from storage and allowed to die. 40

The dramatic contrast in the lay language of the West Australian website-with its explicit reference to embryo death-and the hedging and diffident approach of the Victorian legislation alerts us to the undecidability of the embryo for those institutions charged with task of assessing and determining the conditions of its disposal. Even in Victoria, where some attempt has been made to regulate this process, there is no indication of what is to be done with the contents of the container after the twenty-four-hour period has elapsed.

As human tissue, embryo disposal, in the context of medical treatment, would generally fall within local guidelines on the disposal of clinical waste. 41 However, all IVF clinics in Australia are required to comply with the National Health and Medical Research Council, Ethical Guidelines on the Use of Assisted Reproductive Technology in Clinical Practice and Research (NHMRC ART Guidelines) in order to obtain accreditation by the Reproductive Technology Accreditation Committee, a statutory requirement. ${ }^{42}$ These guidelines make it clear that the embryo cannot be treated in the same manner as other forms of medical waste. Paragraph 8.9 requires 
a measure of 'respect' in terms of the handling of embryos. Under the heading 'Dispose of embryos respectfully', the NHMRC ART Guidelines direct clinics to have 'protocols in place for the respectful disposal of embryos'. Further, at 8.9.1, they require that the 'wishes of the persons for whom the embryos are stored, as to the method of disposal, should be respected'.

This disposition requirement is based on paragraph 5.2 of the same document, which relies upon 'one very widely shared view' that 'embryos warrant very serious moral consideration'. More generally, the guidelines direct clinics to deal with embryos 'according to these guidelines and accepted standards of clinical and laboratory practice'. This hands the burden of defining respect in practical terms back to the clinic. What is stipulated in the NHMRC ART Guidelines is an ethical attitude towards the embryo tied to the enacted expression of some appropriate affect or, at a minimum - one might imagine-the suppression of other, inappropriate forms of affect on the part of the clinician. This draws the clinician into a nascent death scene governed by the expectation that they will maintain a proper level of moral seriousness when handling the embryo.

This is particularly interesting given the origin of the practice of 'compassionate transfer' in the Swiss clinics described earlier. Translating what was essentially a means to circumvent a law that insisted on retaining and transferring all embryos, into an ethical and compassionate act is a deft rhetorical manoeuvre, effectively interpolating female reproductive anatomy into the legislation. Placing embryos internally follows the letter of the Swiss law, if not the letter of the body. While these methods were originally aimed at ways around the law (anatomy as loophole) they have subsequently been adopted by clinics in other countries including the United States and by the women who use their services as a means to dispose of their embryos in a way that acknowledges embryo loss.

The language used to describe this process-compassionate transfer-is troubling. If placing embryos inside the woman's body in one context (that of hopeful reproductivity) defines the purpose of the clinic, then what of this scene, where a similar procedure signals the inverse? Or, to return to the question raised at the beginning: who extends compassion to whom? 
-WHO EXTENDS COMPASSION TO WHOM (OR WHAT)?

In the practice of so-called compassionate transfer, the transfer is not just of the embryo but also of the ethic of compassionate care itself. It is transferred from the realm of mandated respectful attitudes, to the realm of the woman's body that already knows of care and loss and becoming. This transfer also signals another shift away from the master temporality of the clinic that brings bodies under its aegis, that regulates fertility cycles through hormonal interventions, that disciplines them against wasteful practise. Instead, it permits the return to the temporality of the body, its own cycles and flows, its multiple productions and depletions that occur irrespective of the clinic's demands. In so doing, perhaps the clinic reaps an additional benefit by distinguishing this particular death as if it were a discrete occurrence and not indicative of the IVF process as a whole-a process that rests on a logic of surplus (and all that implies) as a defence against the statistically small success rate for pregnancies carried to term.

In Sheryl De Lacey's study she describes how embryo implantation and survival was perceived by participants in what she describes as the 'discard' group to be 'a matter of chance'.43 De Lacey goes on to note: 'It was evident that many in the "Discard" group had experienced a pregnancy loss in the form of a miscarriage or blighted ovum. Several participants also referred to various uncertainties intrinsic to IVF treatment and their perception of embryo loss as normal.' 44

De Lacey quotes 'Anne-Marie':

For me it was much like the miscarriages [we had]. It's like a sense of lost opportunity in that there was a kid that we'd never met. That's the way I looked at it and I just sort of thought well yes, if I treat it like that, that's the way I'll handle it. Saying goodbye to this embryo was much the same except it was within our control.

'Bee', a blogger who writes on her experience of IVF treatment, also drew on this idea of the naturalness of loss but tellingly described her own sense of embodied performance of holding and connecting to her embryos through this process:

So we have chosen the third option, commonly called 'compassionate transfer' in which the embryos are thawed and placed in my body at a time and using a method that cannot produce a pregnancy. 
It's a strange choice when you think about it. What does it matter whether the embryos stop growing in a dish, in the laboratory, or inside my body?

My obstetrician, who is also a friend, put this in context for me: 'More often than women will ever know, fertilized eggs "roll on through" and do not implant. It's the way nature works.' In fact, that is exactly what happened to the embryos we transferred with Madelyn's and Lily's embryos, that did not grow into children. By choosing compassionate transfer, I will be putting our remaining embryos back where they would have been if naturally conceived, but not implanted.

And the mother in me, as I think about the children who are not but might have been, simply wants to hold them for that brief time. And say goodbye. 45

If this is the means to produce an ethical and respectful end how, if at all, is this goal achieved? On the one hand it suggests the role of the maternal body, even as it fails to mother-a guarantee of contact between the surrendered (doomed) embryo and the respectful care of maternal flesh.

But these kinds of transition rituals dedicated to entities that have not yet lived should not be equated with ceremonies one would offer a lost child but rather, we suggest, might represent attempts to recognise and register value in women's experience of the creation of these embryos; the physical and emotional effort that has gone into wanting and making them. In this way, both life and death for embryos are by no means objectively, scientifically, legally identifiable moments. Instead, they might be described as investments-made typically by women but also by other parental figures-in that which is desired. Seen this way it is the desire of these figures that should be considered as enabling the performance of this end scene-perhaps even just to mourn the loss of that desire.

David Ellison is a senior lecturer in the School of Humanities at Griffith University. He is currently working on a cultural history of Victorian domestic discomfort. 
Isabel Karpin is a professor of Law at the University of Technology, Sydney. She researches in Health Law, Feminist Legal Theory, and Law and Culture. She is involved in major research projects in reproductive technology, disability and emergent genetic technologies.

\section{-NOTES}

1 In 2006, there were 118,700 embryos in storage in Australia (NHMRC: Facts and Figures on embryos licenses and funding, <http://www.nhmrc.gov.au/research/embryos/stemcells/index.htm\#> (last accessed 15 August 2010).

2 Research Involving Human Embryos Act (Cth.) 2002 s10(2), however 'succumb' is not defined. ${ }^{3}$ National Health and Medical Research Council, Ethical Guidelines on the Use of Assisted Reproductive Technology in Clinical Practice and Research, June 2007 (hereafter NHMRC ART Guidelines) <http://www.nhmrc.gov.au/publications/synopses/e78syn.htm>.

4 Western Australian Reproductive Technology Council website, <http://www.rtc.org.au/embryostorage/index.html\#treatment> (last accessed 14 August 2010). 5 The Commonwealth guidelines limit storage to five years with an option to renew for a further five years. The NHMRC ART Guidelines state at paragraph 8.8: 'It is not desirable to leave embryos in storage indefinitely. Clinics must have clear policies that limit the duration of storage of embryos.' Paragraph 8.8.1 provides more detailed guidance, stating: 'The maximum time for which embryos may be kept in storage should be five years with the option to renew consent for a further five years.' In New South Wales the Assisted Reproductive Technology Act 2007, s 25(3)(c) limits the storage period for embryos 'created using a donated gamete' to a period of ten years from the date the gamete was obtained from the donor (plus any additional period that may be authorised by the Director-General. The Victorian Assisted Reproductive Technology Act 2008 requires embryos to be removed from storage after the latest of the following days: (1) the day that is five years after the day the embryo is placed in storage (s33(2)(b)(i)); (2) the day that is ten years after the day the embryo is place in storage, if the original gamete providers extend their consent for an additional five year storage period after the first five years of embryo storage(s33(2)(b)(ii)); OR (3) if the Patient Review Panel has found there to be reasonable grounds for a longer storage period (than the ten years), the day that is the end of the period approved by the panel (ss33(2)(b)(iii) \& 33(3)). The Western Australian Human Reproductive Technology Act 1991 sets a maximum period of storage as ten years, unless the council approves an application by an eligible person, for a longer period (s24(1)). The South Australia Reproductive Technology (Clinical Practices) Act also had a ten-year maximum storage limit; however, amendments that came in to force in September 2010 have removed this provision and the NHRMC ART Guidelines 
now apply. Note also the South Australian Act is now called the Assisted Reproductive Treatment Act 1988.

${ }^{6}$ As will be discussed below, transfer to the woman's body is largely a US practice although there is anecdotal evidence that clinics in Australia are considering it. For the US practice, see Alison Lobron, 'The Maybe-Baby Dillema', Boston Globe, 22 November, 2009,

<http://www.boston.com/bostonglobe/magazine/articles/2009/11/22/the_maybe_baby_dilemma/> (last accessed 15 August 2010).

${ }^{7}$ A.D. Lyerly, K. Stteinhauser, C. Voils, E. Namey, C. Alexander, B. Bankowski, R. Cook-Deegan, W.C. Dodson, E. Gates, E.S. Jungheim, P.G. McGovern, E.R. Myers, B. Osborn, W. Schlaff, J. Sugarman, J.A. Tullsky, D. Walmer, R.R. Faden, E. Wallach, 'Fertility Patients' Views about Frozen Embryo Disposition: Results of a Multi-institutional US Survey', Fertility and Sterility, vol 93, no. 2, 2010 (published online 2008), pp. 499-509.

${ }^{8}$ Resolve <http://www.resolve.org/family-building-options/donor-options/after-ivf-the-embryodecision.html> (last accessed 15 August 2010).

${ }^{9}$ Meichum Mohler-Kuo et al., 'Attitudes of Couples towards the Destination of Surplus Embryos: Results among Couples with Cryopreserved Embryos in Switzerland', Human Reproduction, vol. 24, no. 8, 2009, pp. 1930-8. Note that before 2001 cyropreservation of embryos for later use was routine, however, the Medical Assistance to Reproduction Act also introduced a deadline was for the destruction of those previously cryopreserved embryos. In 2005 the Swiss government introduced legislation to allow for cryopreservation in very limited circumstances for the purposes of research use only. See the Swiss Stem Cell Research Act.

10 The Swiss Constitutions section 119(2)c, available in English at The Federal Authorities of the Swiss Confederation Website <http://www.admin.ch/ch/e/rs/101/index.html> (last accessed 2 February 2011).

11 Bruno Imthurn, director of the Division of Reproductive Endocrinology and the Department of Obstetrics and Gynaecology at the University Hospital Zurich, notes: 'Today the culture and the scoring system have progressed. And it is now possible to score reliably on day 1 the 2PNS. So most centres in Switzerland develop only 2 2PNS to embryos. That means that intravaginal replacement has been abandoned by most Swiss centres.' Personal email, 25 March 2009 (quoted with permission). 12 Interview with 'H.', 2007 in Jackie Leach Scully, Rouven Porz and Christoph Rehmann-Sutter, 'Heirs and Spares: On Making Up Embryos', paper presented at the International Conference on 'The Healthy Embryo', Western University, Canada, 14 November 2007); see also Jackie Leach Scully, Christoph Rehmann-Sutter and Rouven Porz, 'Embryos in the Plural: Donors' and Non-donors' Perspectives on Embryo Moral Status' in Jeff Nisker, Francoise Bayliss, Isabel Karpin, Carolyn McLeod and Roxanne Mykitiuk (eds), The 'Healthy' Embryo: Social, Biomedical, Legal and Philosophical Perspectives, Cambridge University Press, Cambridge, 2010, and Erica Haines, Rouven Porz, Jackie Leach Scully, Christoph Rehmann-Sutter, “'So, What is an Embryo?" A Comparative Study of the Views of Those 
Asked to Donate Embryos for hESC Research in the UK and Switzerland', New Genetics and Society, vol. 27, no. 2, 2008, pp. 113-26.

13 Bruno Imthurn, email, 29 October 2009 (quoted with permission).

14 Lyerly et al.; Sheryl De Lacey, 'Patients' Attitudes to their Embryos and their Destiny: Social

Conditioning?', Best Practice and Research in Clinical Obstetrics and Gynaecology, vol. 21, no. 1, 2007, pp.

101-12; Sheryl De Lacey, 'Decisions for the Fate of Frozen Embryos: Fresh Insights into Patients'

Thinking and their Rationales for Donating or Discarding Embryos', Human Reproduction, vol. 22, 2007, pp. 1751-8; Erica Haimes and Ken Taylor, 'Fresh Embryo Donation for Human Embryonic Stem Cell (hESC) Research: The Experiences and Values of IVF Couples Asked to be Embryo Donors, Human Reproduction, vol. 24, no. 9, 2009, pp. 2142-50.

15 Isabel Karpin 'The Uncanny Embryos: Legal Limits to the Human and Reproduction without Women', Sydney Law Review, vol. 28, no. 4, 2006, pp. 599-623 at p. 603.

16 De Lacey, 'Decisions for the Fate of Frozen Embryos', at p. 1756.

17 De Lacey, 'Decisions for the Fate of Frozen Embryos', at p. 1756.

18 See 'Snowflakes' a website that arranges adoptions of frozen embryos

<http://www.nightlight.org/adoption-services/snowflakes-embryo>.

${ }^{19}$ Fenella Souter, 'Maybe Baby', Sydney Morning Herald, 13 June 2009, p. 19.

${ }^{20}$ Haimes and Taylor, 'Fresh Embryo Donation for Human Embryonic Stem Cell (hESC)', pp. 2142-50.

21 See note 1 , above.

22 Y. Wang, G. Chambers, M. Dieng and E. Sullivan, Australian Reproductive Technology in Australia and New Zealand, Australian Institute of Health and Welfare National Perinatal Statistics Unit, Sydney, 2007: <http://www.aihw.gov.au/publications/index.cfm/title/10753>.

23 This claimed the practice of visual assessment of embryos (which has not been scientifically validated) may soon become obsolete with the development of new microarray technologies. See Jill Stark, 'New IVF Technique Set to Lift Birth Rates', Age, 24 October 2010.

24 Estair Van Wagner, Roxanne Mykitiuk and Jeff Nisker note, for instance, that while some IVF clinics 'still use microscopic criteria to determine which embryos are the "healthiest looking", and transfer the "best" embryos while "fresh", in order to achieve the highest pregnancy rate ... there is no evidence that an embryo's potential to become a child can be conclusively determined using morphological characteristics viewable through a microscope', Estair Van Wagner, Roxanne Mykitiuk and Jeff Nisker, 'The 'Affected' Post-Preimplantation Genetic Diagnosis Embryo' in Belinda Bennett, Terry Carney and Isabel Karpin (eds), Brave New World of Health, Federation Press, Sydney, 2008, pp. 37-54.

Nevertheless, these kinds of qualitative decisions continue. For instance, in Denmark, Svendsen and Koch describe the way 'laboratory technicians and clinicians classified the cultured embryos, some were described as "good-looking" or even "beautiful" and considered well suited for implantation. Others were described as "looking ugly in the microscope" or simply as "not good-looking", which meant that they might have a chromosome disorder or a similarly serious condition.' They go on to 
argue that by naming embryos 'ugly', 'not so nice',' good-looking' or 'beautiful', 'clinicians classified the possible future of harvested embryos and negotiated their destinies', Mette N. Svendsen and Lene Koch, 'Unpacking the "Spare Embryo": Facilitating Stem Cell Research in a Moral Landscape', Social Studies of Science, vol. 38, no. 93, 2008, p. 99.

25 See NHMRC ART Guidelines, chapter 12. See also Van Wagner, Mykitiuk and Nisker.

26 Similarly, Roberts, who undertook an ethnographic study of IVF clinics in Ecuador, states 'neither practitioners nor patients considered poor-quality embryos to be worthy of mention, or cyropreservation'. These fragmented or asymmetrical embryos were described as ' $f e o$ ', or ugly. Elizabeth F. S. Roberts, 'Extra Embryos: The Ethics of Cryopreservation in Ecuador and Elsewhere', American Ethnologist, vol. 34, no. 1, 2007, pp. 181-99.

27 Robert Shabanowitz, 'The Disposer's Dilemma', American Journal of Bioethics, no. 5, 2005, pp. 60-1, at p. 60 .

${ }^{28}$ See section 7(1) of the Research Involving Human Embryos Act 2002 which states 'unsuitable for implantation, in relation to a human embryo, means a human embryo that (a) is diagnosed by preimplantation genetic diagnosis as unsuitable for implantation ... or (b) is determined to be unsuitable for implantation in the body of a woman, in accordance with objective criteria specified in guidelines issued by the CEO of the NHMRC under the National Health and Medical Research Council Act 1992 and prescribed by the regulations for the purposes of this paragraph.'

${ }^{29}$ See Monash IVF fact sheet 'Embryo freezing/thawing' for an example of how this process works in practice <http://www.monashivf.com/default.asp?action=article\&ID=21836> (last accessed 2 February 2011).

${ }^{30}$ Notably, the embryo itself is far from an agreed upon entity. As far as the legal definition is concerned, it differs from jurisdiction to jurisdiction. In Australia the federal government has refined its definition of an embryo over the last five years so that it comes into being only after the first cell division has occurred. See for example the Prohibition of Human Cloning for Reproduction Act 2002 (Cth), s 8 and Research Involving Human Embryos Act 2002 (Cth), s 7: 'human embryo means a discrete entity that has arisen from either:

(a) the first mitotic division when fertilisation of a human oocyte by a human sperm is complete; or

(b) any other process that initiates organised development of a biological entity with a human nuclear genome or altered human nuclear genome that has the potential to develop up to, or beyond, the stage at which the primitive streak appears;

and has not yet reached 8 weeks of development since the first mitotic division.'

31 Souter, p. 19 quoting Archibald.

32 Andy Coghlan, 'Does Arrested Development Equal Embryo Death?', New Scientist, 25 September 2006 $<$ http://www.newscientist.com/article/dn10153-does-arrested-development-equal-embryodeath.html> (last accessed 16 October 2009). 
33 David Wasserman, 'What Qualifies as a Live Embryo?', American Journal of Bioethics, no. 5, 2005, p. 24.

34 De Lacey, 'Patients Attitudes to their Embryos,' p. 104.

35 See note 5 , above.

${ }^{36}$ Assisted Reproductive Treatment Act 2008 (Vic) s 34(2)(b).

${ }^{37}$ Assisted Reproductive Treatment Regulations 2009 (Vic.) reg 12.

38 Reproductive Technology (Clinical Practices Act) 1988 (SA).

${ }^{39}$ Reproductive Technology (Clinical Practices) (Miscellaneous) Amendment Act 2009 (SA).

$40<$ http://www.rtc.org.au/embryostorage/index.html\#treatment> (last accessed 13 August 2010).

41 In New South Wales, for instance, clinical waste is defined to include human tissue used in treatment excluding hair, teeth and nails. See Waste Classification Guidelines Part 1: Classifying Waste, NSW

Department of Environment and Climate Change, New South Wales, p. 3,

<http://www.environment.nsw.gov.au/resources/waste/08202classifyingwaste.pdf>.

42 Research Involving Human Embryos Act 2002 (Cth.) s11 and various Australian state acts.

43 De Lacey, 'Decisions for the Fate of Frozen Embryos', p. 1755.

44 De Lacey, 'Decisions for the Fate of Frozen Embryos', p. 1756.

45 Bee, comment on 'Left over Embryos: What to do?', Hard Boiled: A Donor Egg Blog, comment posted 5 March 2009, < http://www.donoreggblog.com/2009/03/left-over-embryos-what-to-do.html> (last accessed 16 October 2009). 